\title{
New isolations of the rabies-related Mokola virus from South Africa
}

\author{
Jessica Coertse ${ }^{1} \mathbb{D}$, Wanda Markotter ${ }^{1}$, Kevin le Roux ${ }^{2}$, Daniel Stewart ${ }^{3}$, Claude T. Sabeta ${ }^{4}$ and Louis H. Nel ${ }^{5^{*}}$
}

\begin{abstract}
Background: Mokola virus (MOKV) is a rabies-related lyssavirus and appears to be exclusive to the African continent. Only 24 cases of MOKV, which includes two human cases, have been reported since its identification in 1968. MOKV has an unknown reservoir host and current commercial vaccines do not confer protection against MOKV.

Results: We describe three new isolations of MOKV from domestic cats in South Africa. Two cases were retrospectively identified from 2012 and an additional one in 2014.

Conclusions: These cases emphasize the generally poor surveillance for rabies-related lyssaviruses and our inadequate comprehension of the epidemiology and ecology of Mokola lyssavirus per se.
\end{abstract}

Keywords: Mokola virus, Lyssavirus, Rabies-related, South Africa

\section{Background}

The Lyssavirus genus currently consists of 14 recognized species all capable of causing rabies, a fatal encephalitic disease. The prototype species of this genus is Rabies lyssavirus and the rest are known as the rabies-related lyssaviruses [1]. Mokola virus (MOKV), a rabies-related lyssavirus, was first isolated from shrews in the Mokola forest in Nigeria in the late 1960s [2, 3]. Shortly thereafter, MOKV was reported as the causative agent of a neurological disease in two children from Nigeria $[4,5]$. However, these reports remain controversial for a variety of reasons. The first isolation was made from the cerebrospinal fluid of a 3.5-year-old girl in 1968. The girl recovered without any neurological sequelae while no virus neutralizing antibodies (VNAs) were detected [4]. This is unexpected as reports of patients surviving rabies are exceptionally rare. In the majority of survivor cases the patient is burdened with moderate to severe neurological sequelae $[6,7]$ with VNAs regarded as a primary mechanism of viral clearance $[6,8]$. The second human isolate was obtained from the brain tissue of a 6-year-old girl in 1971 that died from suspected meningitis or encephalitis. In both these human cases clinical symptoms were atypical for classical rabies virus (RABV) infection

\footnotetext{
*Correspondence: louis.nel@up.ac.za

${ }^{5}$ Department of Microbiology and Plant Pathology, Faculty of Natural and Agricultural Sciences, University of Pretoria, Pretoria 0001, South Africa Full list of author information is available at the end of the article
}

[5]. It is doubtful that these isolates are still in existence and no genetic information is available [9].

Up until 2013, only 18 confirmed MOKV isolations, from a variety of mammalian host species including shrews, cats, dogs and a rodent (Lophuromys sikapusi), were known to exist [9]. MOKV was first encountered in South Africa in 1970, when the virus was isolated from a domestic cat in the KwaZulu-Natal (KZN) province [10]. In 1981, it became evident that the available rabies vaccines did not confer protection against MOKV when this virus was isolated from vaccinated cats and a dog in Zimbabwe [11]. It appears that MOKV is exclusive to the African continent and all isolations for the last 20 years have been made from southern Africa. Little is known about the epidemiology of this lyssavirus and the problem is compounded by an unknown reservoir and limited surveillance throughout the continent. In the few instances where rabies diagnostic facilities are available and operational in Africa, only the fluorescent antibody test (FAT) is used. The FAT relies on the use of a polyclonal fluorescein isothiocyanate conjugated antilyssavirus globulin that is capable of detecting all known lyssavirus species but cannot distinguish between them. As a result, positive cases are reported as rabies but the actual causative lyssavirus species is rarely identified. In South Africa, where molecular characterization of FATpositive samples is frequently done, the majority of MOKV isolations have been from the $\mathrm{KZN}(n=4)$ and 
Eastern Cape (EC) provinces $(n=5)$ with a single isolation reported from the Mpumalanga province. These isolates differ by between $0-5.7 \%$ and $0-2 \%$ at the nucleotide and amino acid levels of the nucleoprotein $(\mathrm{N})$ gene. However, comparison of the $\mathrm{N}$-gene of all known MOKV isolates demonstrated variations of up to $15 \%$ and $6.4 \%$ on the nucleotide and amino acids levels respectively [9].

Rabies virus (RABV) vaccines do not protect against MOKV $[9,11,12]$ and it should be appreciated that the domestic cat is the most commonly MOKV-infected host species. The frequent contact between cats and their owners suggests a potential risk of spill-over infection to humans. Considering this situation, it is clear that a better understanding of the incidence and ecology of MOKV ecology is of utmost importance. Here we report the isolation and characterization of three MOKV isolations from cats from KZN, South Africa, 4 years after the last isolation of this virus in 2008 from South Africa. The first case was identified in January 2014 and subsequently a small retrospective study on selected samples was undertaken, identifying an additional two cases from 2012.

\section{Methods}

\section{The study}

In January 2014, a private veterinarian submitted brain material from a domestic cat that had died of suspected rabies in Pietermaritzburg, KZN, South Africa (laboratory reference number: 14/024) to the Allerton Provincial Veterinary Laboratory. The FAT was performed by staining acetone-fixed impression smears of the brain material with a polyclonal fluorescein isothiocyanate conjugated anti-lyssavirus globulin (OIE Rabies Reference Laboratory of the Agricultural Research Council-Onderstepoort Veterinary Institute (ARC-OVI), South Africa) [13]. Lyssavirus antigen was observed, but in this specific case the staining was of dull fluorescence clearly atypical of rabies virus positive samples. Such atypical staining which has previously been noted in MOKV infections prompted further investigation of this case. The positive FAT result was confirmed at the OIE Rabies Reference Laboratory at Onderstepoort (ARC-OVI, South Africa) and the sample genetically characterized at the University of Pretoria. Following the subsequent identification of sample $14 / 024$ as MOKV, it was decided to investigate and molecularly characterize other FAT positive rabies samples from domestic animals from throughout KZN. Selected archived samples $(n=36)$, were characterized by nucleotide sequencing resulting in the identification of an additional two MOKV cases.
RNA extraction, RT-PCR and phylogenetic analysis Total RNA was isolated from brain material using Trizol reagent (Invitrogen) according to the manufacturer's instructions. The complete $\mathrm{N}$-, phosphoprotein- (P), matrix protein- $(\mathrm{M})$ and glycoprotein $(\mathrm{G})$ genes were sequenced using different primer combinations and cycling conditions (Additional file 1: Table S1) for all MOKV samples. Briefly, reverse transcription was performed for all samples using the following protocol: 10 pmol of forward primer was added to $5 \mu$ l total RNA and incubated at $94{ }^{\circ} \mathrm{C}$ for $1 \mathrm{~min}$. These reactions were cooled on ice for $5 \mathrm{~min}$ followed by reverse transcription for $90 \mathrm{~min}$ at $42{ }^{\circ} \mathrm{C}$ in a final volume of $20 \mu \mathrm{l}$ containing $1 \mathrm{x}$ reverse transcriptase buffer (containing $250 \mathrm{mM}$ Tris- $\mathrm{HCl}, 40 \mathrm{mM} \mathrm{MgCl} 2,150 \mathrm{mM} \mathrm{KCl}, 5 \mathrm{mM}$ dithiothreithol, Roche), $2.2 \mu \mathrm{l}$ dNTP mix (10 mM, Promega), 8 $\mathrm{U}$ Avian myeloblastosis virus reverse transcriptase (Roche) and $16 \mathrm{U}$ Recombinant RNasin Ribonuclease inhibitor (Promega). The genes were subsequently amplified using $20 \mu \mathrm{l}$ cDNA in a final volume of $100 \mu \mathrm{l}$ containing $1 \mathrm{x}$ DreamTaq Buffer (containing $\mathrm{KCl}$, $(\mathrm{NH} 4)_{2} \mathrm{SO}_{4}$ and $20 \mathrm{mM} \mathrm{MgCl}$, Thermo Scientific), 10 pmol of forward primer (Additional file 1: Table S1), 12.5 pmol reverse primer (Additional file 1: Table S1) and 1.25 U DreamTaq DNA polymerase (Thermo Scientific). Analysis and sequencing of PCR products were performed as described previously [14]. Nucleotide sequences were edited and assembled using BioEdit Sequence Alignment Editor Version 7 [15]. The partial $\mathrm{N}$-gene for RABV sequences (Additional file 2: Table S2) or concatenated and individual genes for MOKV sequences (Additional file 3: Table S3) was analyzed with jModeltest 2 [16] for each dataset to determine the most appropriate substitution model. Data was analyzed using BEAST v.1.8 [17] using a random starting tree with a strict clock for each dataset and assuming an exponential population growth with Markov Chain Monte Carlo (MCMC) chains of 50 million generations.

\section{Virus isolation}

Virus was isolated from MOKV samples on murine neuroblastoma cells as described previously [18].

\section{Results}

The partial N-gene sequences (using primers 001lys/ 550B, Additional file 1: Table S1) [19] of the 36 samples were determined and subsequent to the analyses two more MOKV cases were identified i.e. 12/458 and 12/ 604 (Table 1). Based on partial N-gene sequences, the remaining 33 archival samples were determined to be the canid variant of RABV. Bayesian analysis indicated that all new RABV sequences group with other RABV sequences from the same time period (Fig. 1). 
Table 1 Information of domestic animals from the KwaZulu-Natal province submitted for molecular characterization

\begin{tabular}{|c|c|c|c|c|}
\hline Laboratory reference number & Host & Collection area & Date & Genbank accession number (gene) \\
\hline $07 / 30$ & Felis catus (feline) & Empangeni & $11 / 01 / 2007$ & KP994621 \\
\hline $07 / 76$ & Felis catus (feline) & Melmoth & $29 / 01 / 2007$ & KP994616 \\
\hline 08/105 & Felis catus (feline) & Kwadukuza & 18/02/2008 & KP994617 \\
\hline $08 / 426$ & Felis catus (feline) & Jozini & 03/07/2008 & KP994618 \\
\hline $08 / 642$ & Felis catus (feline) & Exodondakukuska & $15 / 10 / 2008$ & KP994619 \\
\hline 09/353 & Felis catus (feline) & Nkambanana & 07/08/2009 & KP994620 \\
\hline $10 / 268$ & Canis familiaris (canine) & Umdoni & 20/05/2010 & KJ744302 \\
\hline $10 / 274$ & Canis familiaris (canine) & Hibiscus coast & $24 / 05 / 2010$ & KJ744308 \\
\hline 10/387 & Canis familiaris (canine) & Umzumbe & 23/08/2010 & KJ744303 \\
\hline $10 / 458$ & Capra aegagrus hircus (goat) & Umzimkulu & 29/09/2010 & KJ744309 \\
\hline $10 / 509$ & Canis familiaris (canine) & Mkhambathini & $22 / 10 / 2010$ & KJ744304 \\
\hline $10 / 598$ & Felis catus (feline) & Dundee & $16 / 11 / 2010$ & KP994606 \\
\hline $11 / 28$ & Canis familiaris (canine) & Richmond & $14 / 01 / 2011$ & KP994597 \\
\hline $11 / 185$ & Canis familiaris (canine) & Mkahambathini & 24/03/2011 & KJ744305 \\
\hline $11 / 195$ & Canis familiaris (canine) & Mkhambathini & 28/03/2011 & KP944598 \\
\hline $11 / 217$ & Canis familiaris (canine) & Umdoni & $12 / 04 / 2011$ & KJ744310 \\
\hline $11 / 300$ & Canis familiaris (canine) & Richmond & $30 / 05 / 2011$ & KJ744307 \\
\hline $11 / 419$ & Felis catus (feline) & Ethekweni & 16/08/2011 & KP994607 \\
\hline $12 / 069$ & Felis catus (feline) & Okhalamba & $31 / 01 / 2012$ & KP994610 \\
\hline $12 / 458$ & Felis catus (feline) & Durban & $13 / 06 / 2012$ & $\begin{array}{l}\text { KP899610(N), KP899619(P), } \\
\text { KP899613(M), KP899616(G) }\end{array}$ \\
\hline $12 / 604$ & Felis catus (feline) & Durban & 08/07/2012 & $\begin{array}{l}\text { KP899611(N), KP899620(P), } \\
\text { KP899614(M), KP899617(G) }\end{array}$ \\
\hline $12 / 696$ & Felis catus (feline) & Ethekweni & $27 / 07 / 2012$ & KP994608 \\
\hline $12 / 903$ & Felis catus (feline) & Okhahlamba & 02/10/2013 & KP994609 \\
\hline $13 / 058$ & Felis catus (feline) & Ethekweni & $25 / 01 / 2013$ & KP994611 \\
\hline $13 / 079$ & Canis familiaris (canine) & Umlazi & $01 / 02 / 2013$ & KP994601 \\
\hline $13 / 104$ & Canis familiaris (canine) & Amanzimtoti & $14 / 02 / 2013$ & KP994599 \\
\hline $13 / 107$ & Canis familiaris (canine) & Westville & 18/02/2013 & KP994602 \\
\hline $13 / 167$ & Canis familiaris (canine) & Adams mission & 18/03/2013 & KP994612 \\
\hline $13 / 256$ & Canis familiaris (canine) & Amanzimtoti & 09/05/2013 & KP994613 \\
\hline $13 / 310$ & Canis familiaris (canine) & Umkomaas & 10/06/2013 & KP994603 \\
\hline $13 / 339$ & Canis familiaris (canine) & Umlazi & $21 / 06 / 2013$ & KP994614 \\
\hline $13 / 355$ & Canis familiaris (canine) & Amanzimtoti & 28/06/2013 & KP994615 \\
\hline $13 / 522$ & Canis familiaris (canine) & Athlone Park & 27/09/2013 & KP994604 \\
\hline $13 / 525$ & Canis familiaris (canine) & Lewis Drive & 30/09/2013 & KP994605 \\
\hline $13 / 589$ & Canis familiaris (canine) & Uthukela & 29/10/2013 & KP994600 \\
\hline $14 / 024$ & Felis catus (feline) & Pietermaritzburg & 09/01/2014 & $\begin{array}{l}\text { KP899612(N), KP899621(P), } \\
\text { KP899615(M), KP899618(G) }\end{array}$ \\
\hline
\end{tabular}

Details and clinical history of the cats that tested positive for MOKV are summarized in Table 2. For all the MOKV cases, the complete sequences of four structural genes (i.e. N-, P-, M- and G genes) were determined.

For all the MOKV cases, the complete coding region sequence of four structural genes (i.e. N-, P-, M-, and
G-genes) were determined. Each dataset (concatenated or individual genes) were analysed using a Bayesian approach. The tree topology (Fig. 2) observed was similar irrespective of the gene used for analysis (Additional file 4: Figure S1, Additional file 5: Figure S2, Additional file 6: Figure S3, Additional file 7: Figure S4) with the exception 


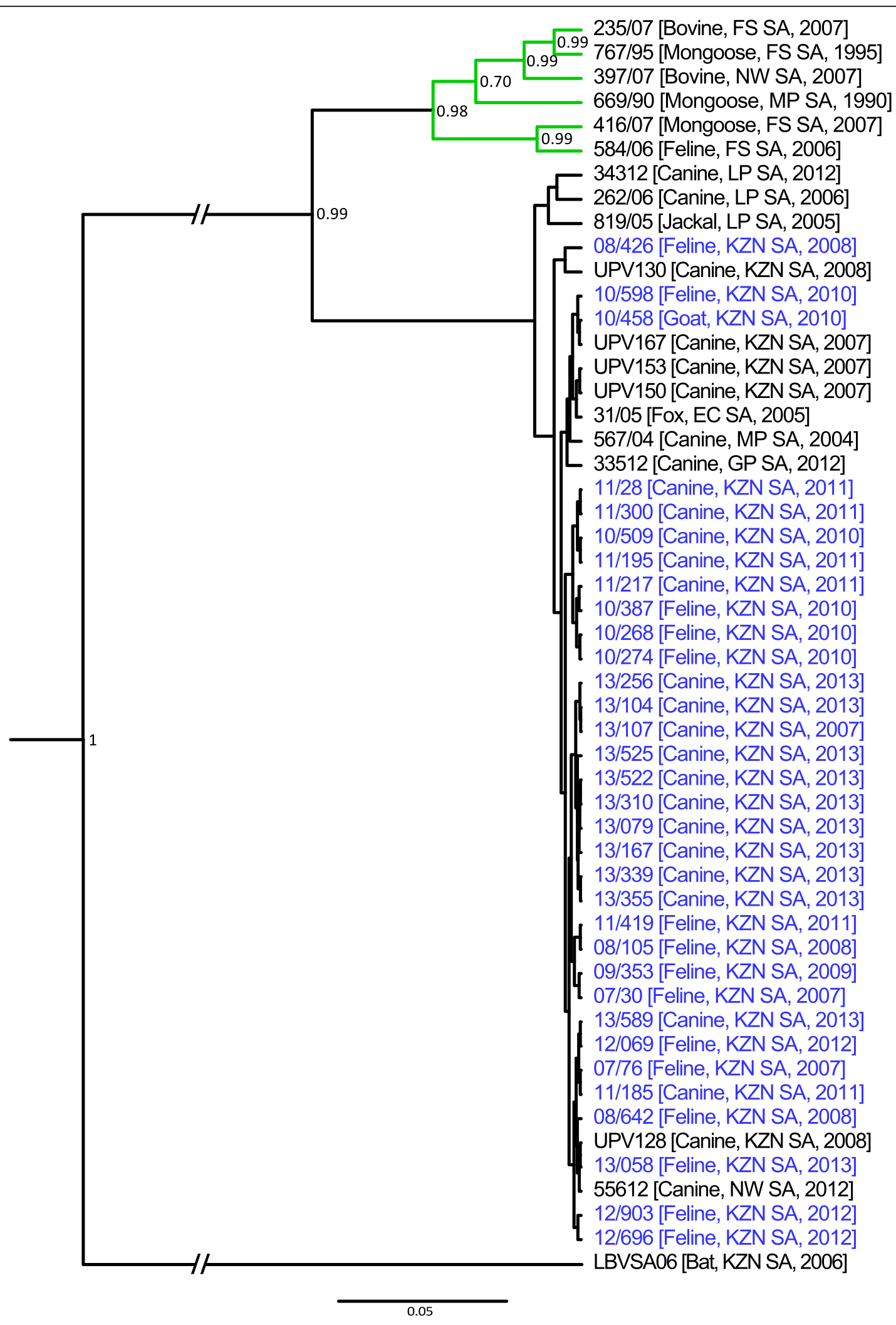

Fig. 1 (See legend on next page.) 
(See figure on previous page.)

Fig. 1 Bayesian analysis of the partial N-gene sequences $(540 \mathrm{bp})$ of the 33 archival samples and other rabies virus sequences from South Africa (Additional file 2: Table S2) applying the general time reversible substitution model with gamma distribution. Laboratory reference numbers are shown for all sequences, followed by the host species, country of origin (EC SA: Eastern Cape province, South Africa; FS SA: Free State province, South Africa; GP SA: Gauteng province, South Africa; KZN SA: Kwa-Zulu Natal province, South Africa; LP SA: Limpopo province, South Africa; MP SA: Mpumalanga province, South Africa; NW SA: North West province, South Africa) and year. All rabies virus sequences determined in this study are indicated in blue

of the M-gene. For the M-gene dataset (Additional file 6: Figure S3), isolate RV4 (from Nigeria) grouped with an isolate from Zimbabwe (posterior probability $=0.8144$ ) and not with the isolate from the Central African Republic as observed for the other datasets. This support findings from previous studies that MOKV phylogeny is strongly influenced by geographical derivation [9]. For the isolates from South Africa, two separate clusters were found to represent isolates from the two provinces viz. KZN and EC. Within the KZN cluster, the new MOKV isolates form a well-supported new clade. Nucleotide divergence of all known MOKV isolates (Additional file 8: Table S4, Additional file 9: Table S5, Additional file 10: Table S6 and Additional file 11: Table S7) ranged from 0.1-13.9\%, $0-25.2 \%, 0-17.8 \%$ and $0.2-19.6 \%$ for the N-, P-, M- and G-genes respectively.

\section{Discussion}

There is no active surveillance for rabies-related lyssaviruses in Africa and subsequently the epidemiology of these viruses remains obscure. Rabies, caused by RABV, is endemic in KZN, South Africa and has been tackled through mass vaccination campaigns [20]. As a result, the annual number of suspected and confirmed rabies cases in dogs has decreased due to an enhanced awareness about the disease. This in turn has led to veterinary laboratories and veterinarians identifying unusual cases of animals displaying rabies symptoms. More cases (and isolations) of rabies-related lyssaviruses should occur in future - like the cases described here. Identification of infections caused by rabies-related viruses is important and any additional information may improve our understanding of the epidemiology of these viruses. However, the recommended diagnostic technique for rabies, the FAT, cannot distinguish between the lyssavirus species.
A broad-spectrum polyclonal fluorescein isothiocyanate conjugated anti-lyssavirus globulin, capable of detecting all lyssavirus species, is used in countries with laboratory diagnostics. In some MOKV cases atypical staining, i.e. the inclusions stain less intensely than is usually seen with rabies virus, has been observed [21]; as described for sample 14/024. The identification of a MOKV infection prompted a small retrospective study to determine if other MOKV cases, which did not produce atypical staining with the FAT, were overlooked. Subsequently, 35 samples collected over a 7 year period were tested and two additional MOKV cases from 2012 were identified. The remaining 33 samples were shown to belong to the canid variant of RABV.

In southern Africa, two variants of RABV circulate i.e. the canid variant infecting members of the Canidae family and the mongoose variant infecting members of the Herpestidae [22]. The conserved N-gene used in the Bayesian analysis is not ideally suited to distinguish between closely related viral variants. Nevertheless, the RABV sequences determined in this study all grouped with other canid variant RABV sequences from the same time period which is indicative of the continued rabies epidemical cycle in domestic dogs that was established in 1976 [23].

Bayesian analysis including all known MOKV isolates demonstrated a pattern of grouping of viruses according to geographical origin, irrespective of the gene(s) used; in agreement with previous reports [9]. The South African isolates grouped according to province - KZN and EC cluster. All previous isolates from KZN collected over a 28 year period (1970-1998) displayed a variation of $2.3 \%$ and $0.7 \%$ at the nucleotide and amino acid levels of the $\mathrm{N}$-gene respectively. When comparing the new isolates from 2012-2014 (14 years after the last isolation

Table 2 Details and clinical history of cats from the KwaZulu-Natal province, South Africa that tested positive for Mokola virus

\begin{tabular}{llll}
\hline & Laboratory reference number & & \\
\hline & $14 / 024$ & $12 / 458$ & Durban \\
Location & Pietermaritzburg & Durban & Female, 1-year-old \\
Host details & Male, 4-year-old & Female, 1-year-old & Growling, aggression, ataxia \\
Clinical signs & Fever $\left(>40^{\circ} \mathrm{C}\right)$, ataxia convulsions & Fever $\left(39.6^{\circ} \mathrm{C}\right)$, ataxia, decreased appetite & 6-8 July 2012 \\
Clinical duration & $8-9$ January 2014 & $10-13$ June 2012 & Euthanized after being non-responsive \\
Clinical outcome & Died of the disease & Euthanized after collapsing and being & \\
& & non-responsive & \\
\hline
\end{tabular}




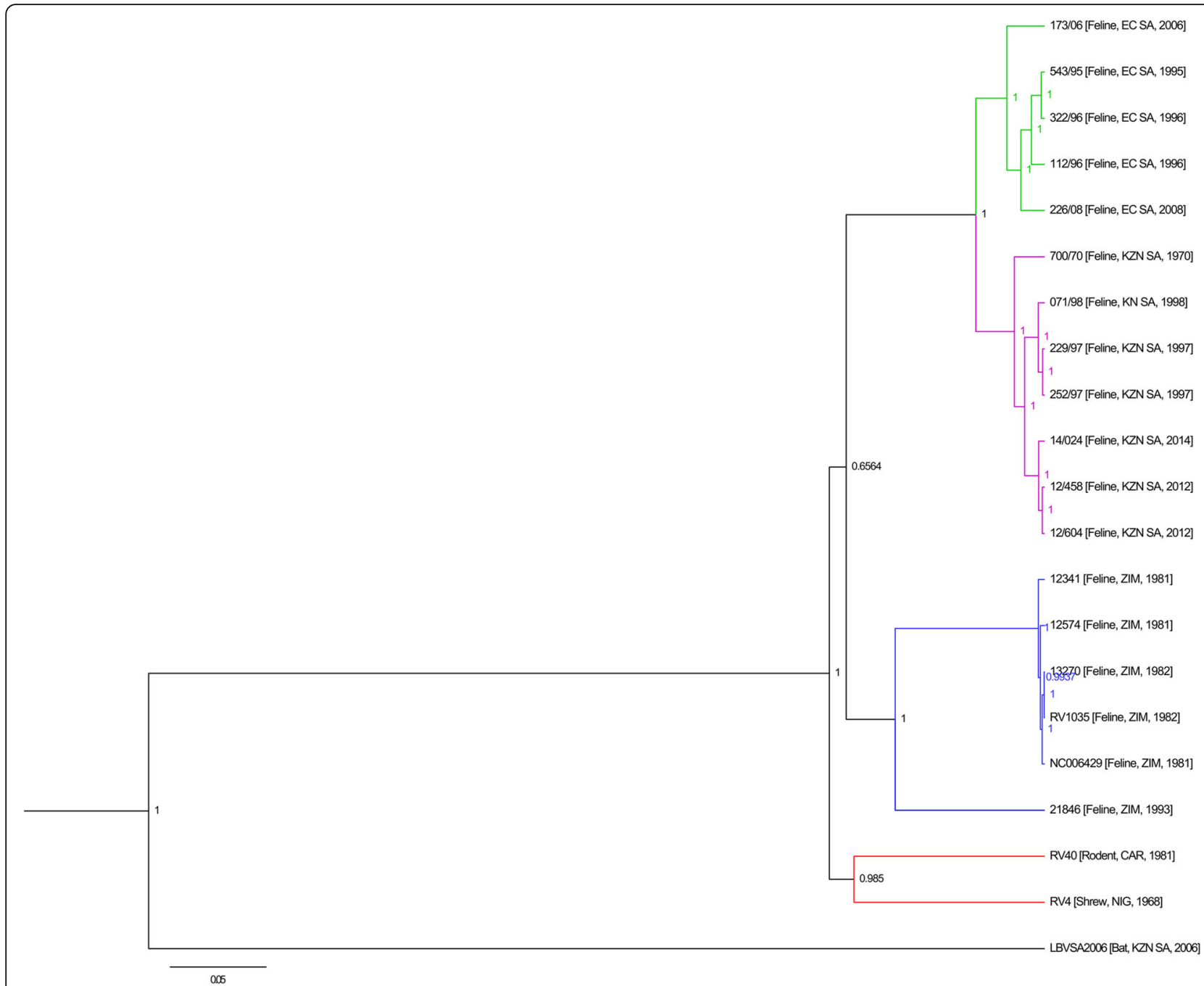

Fig. 2 Bayesian analysis of the concatenated coding region of the $\mathrm{N}-, \mathrm{P}-, \mathrm{M}$ - and G-genes of all Mokola virus isolates (Additional file 3: Table S3) applying the general time reversible substitution model with gamma distribution and invariable sites. Laboratory reference numbers are shown for all sequences, followed by the host species, country of origin (KZN SA: KwaZulu-Natal province, South Africa; EC SA: Eastern Cape province South Africa; ZIM: Zimbabwe; CAR: Central African Republic; NIG: Nigeria) and year of isolation

from KZN) to the previous isolates from KZN, variation of $3 \%$ and $1.1 \%$ is observed at the nucleotide and amino acid levels of the $\mathrm{N}$-gene respectively. Although the monophyletic grouping of South African MOKV isolates is indicative of the continual presence and stability of MOKV [9], the new isolates form a unique and wellsupported clade (posterior probability $=1$ ) within the KZN cluster. These new cases provide yet further confirmation that MOKV cycles are well established and that cases are underreported given the lack of capability/ capacity to routinely characterize rabies positive samples and the lack of rabies surveillance in most developing countries. While the majority of MOKV cases are reported in cats, the identity of the reservoir species is unknown. It has been suggested that the reservoir might be a species that interacts with cats $[9,21]$, but there is little evidence to support this notion. MOKV has been isolated from shrews on three occasions and once from a rodent (Lophuromys sikapusi) and in conjunction with limited pathogenicity studies demonstrating significant amounts of virus in the saliva of shrews and rodents sufficient for transmission, invite speculation that these animals could be possible reservoir hosts [12, 24]. The majority of the lyssaviruses have a strong association with bats, with the exceptions of MOKV and Ikoma lyssavirus [25]. Given the diversity observed for bat lyssaviruses, it has been suggested that bats constitute the main evolutionary hosts [26]. Although MOKV has never been isolated from bats, the possibility of an African bat(s) reservoir cannot be excluded. Nevertheless, the identity of the reservoir host(s) for MOKV remains speculative. The close association of humans 
with domestic cats, an unknown reservoir and the lack of MOKV-protective vaccines [9, 11, 12] collectively support the argument that more research into the epidemiological aspects of MOKV is warranted.

\section{Conclusion}

Considering the close contact of domestic cats with humans and the lack of protection from RABV based commercial vaccines, the risk to public and veterinary health is highlighted. These cases emphasize the lack of surveillance for rabies-related lyssaviruses and as such, the true incidence may be underestimated and is a major contributor to our incomplete understanding of the epidemiology and ecology of MOKV.

\section{Additional files}

Additional file 1: Table S1. Primers and PCR conditions for amplification of the Nucleoprotein-, Phosphoprotein-, Matrix protein- and Glycoprotein genes of Mokola virus isolates. (XLSX $12 \mathrm{~kb}$ )

Additional file 2: Table S2. Details of sequences used for the Bayesian analysis of the rabies virus positive samples. (XLSX $11 \mathrm{~kb}$ )

Additional file 3: Table S3. Details of sequences used for the Bayesian analysis of the new Mokola virus isolates. (XLSX 11 kb)

Additional file 4: Figure S1. Bayesian analysis of the coding region of the Nucleoprotein gene (1353 bp) of all Mokola virus isolates (Additional file 3: Table S3) applying the general time reversible substitution model with invariable sites. Laboratory reference numbers are shown for all sequences, followed by the host species, country of origin (KZN SA: KwaZulu-Natal province, South Africa; EC SA: Eastern Cape province South Africa; ZIM: Zimbabwe; CAR: Central African Republic; NIG: Nigeria) and year of isolation. (TIFF $248 \mathrm{~kb}$ )

Additional file 5: Figure S2. Bayesian analysis of the coding region of the Phosphoprotein gene (913 bp) applying the general time reversible substitution model with gamma distribution. Laboratory reference numbers are shown for all sequences, followed by the host species, country of origin (KZN SA: KwaZulu-Natal province, South Africa; EC SA: Eastern Cape province South Africa; ZIM: Zimbabwe; CAR: Central African Republic; NIG: Nigeria) and year of isolation. (TIFF $222 \mathrm{~kb}$ )

Additional file 6: Figure S3. Bayesian analysis of the coding region of the Matrix protein gene (609 bp) applying the general time reversible substitution model with gamma distribution. Laboratory reference numbers are shown for all sequences, followed by the host species, country of origin (KZN SA: KwaZulu-Natal province, South Africa; EC SA: Eastern Cape province South Africa; ZIM: Zimbabwe; CAR: Central African Republic; NIG: Nigeria) and year of isolation. (TIFF $140 \mathrm{~kb}$ )

Additional file 7: Figure S4. Bayesian analysis of the coding region of the Glycoprotein gene (1569 bp) applying the general time reversible substitution model with gamma distribution and invariable sites.

Laboratory reference numbers are shown for all sequences, followed by the host species, country of origin (KZN SA: KwaZulu-Natal province, South Africa; EC SA: Eastern Cape province South Africa; ZIM: Zimbabwe; CAR: Central African Republic; NIG: Nigeria) and year of isolation. (TIFF 218 kb)

Additional file 8: Table S4. Nucleotide identity of the Nucleoprotein gene of all Mokola virus isolates. (XLSX $10 \mathrm{~kb}$ )

Additional file 9: Table S5. Nucleotide identity of the Phosphoprotein gene of all Mokola virus isolates. (XLSX $10 \mathrm{~kb}$ )

Additional file 10: Table S6. Nucleotide identity of the Matrix protein gene of all Mokola virus isolates. (XLSX $10 \mathrm{~kb}$ )

Additional file 11: Table S7. Nucleotide identity of the Glycoprotein gene of all Mokola virus isolates. (XLSX $10 \mathrm{~kb}$ )

\section{Abbreviations}

ARC-OVI: Agricultural research council-onderstepoort veterinary institute; EC: Eastern Cape province; FAT: Fluorescent antibody test; G-gene: Glycoprotein gene; KZN: KwaZulu-Natal province; MCMC: Markov Chain Monte Carlo; Mgene: Matrix protein gene; MOKV: Mokola virus; N-gene: Nucleoprotein gene; Pgene: Phosphoprotein gene; RABV: Rabies virus; VNAs: Virus neutralizing antibodies

\section{Acknowledgments}

Not applicable.

\section{Funding}

This work was partially funded by the National Research Foundation (Grant UID 92524 \& RISP grant UID78566), the Poliomyelitis Research Foundation (Grant no. 10/40, 12/14) and the Animal and Zoonotic Diseases Institutional Research Theme of the University of Pretoria. The funding sponsors had no role in the design of the study; in the collection, analyses, or interpretation of data; in the writing of the manuscript, and in the decision to publish the results.

\section{Availability of data and materials}

All sequencing data generated during this study are available in the Genbank repository, http://www.ncbi.nlm.nih.gov. Accession numbers are included in this published article [and its Additional files].

\section{Authors' contributions}

J.C., W.M. and L.H.N. conceived and designed the experiments, K.L.R. and D.S. collected samples for molecular characterization and compiled case histories, C.T.S. confirmed FAT results and assisted in obtaining samples for molecular characterization, J.C. performed the experiments and analyzed the data, J.C., W.M., and L.H.N. wrote the paper. All authors read and approved the final manuscript.

\section{Competing interests}

The authors declare that they have no competing interests.

\section{Consent for publication}

Not applicable. Rabies is a controlled animal disease in South Africa. According to legislature all suspected rabies cases must be reported and investigated. Therefore, veterinarians are legally obligated to notify the responsible authorities and collect and submit samples for laboratory investigation.

Ethics approval and consent to participate

Ethical approval for this study was granted by the University of Pretoria Animal Ethics Committee (EC055-14).

\section{Author details}

${ }^{1}$ Center for Viral Zoonoses, Department of Medical Virology, School of Medicine, Faculty of Health Sciences, University of Pretoria, Pretoria 0001, South Africa. ${ }^{2}$ Allerton Provincial Veterinary Laboratory, Pietermaritzburg, KwaZulu-Natal 3200, South Africa. ${ }^{3}$ Department of Agriculture and Environmental Affairs, KwaZulu-Natal Rabies Project, Pietermaritzburg, KwaZulu-Natal, South Africa. ${ }^{4}$ Agricultural Research Council-Onderstepoort Veterinary Institute (ARC-OVI), Pretoria 0110, South Africa. ${ }^{5}$ Department of Microbiology and Plant Pathology, Faculty of Natural and Agricultural Sciences, University of Pretoria, Pretoria 0001, South Africa.

Received: 9 August 2016 Accepted: 12 January 2017

Published online: 31 January 2017

\section{References}

1. Afonso CL, Amarasinghe GK, Bányai K, Bào Y, Basler CF, Bavari S, et al. Taxonomy of the order Mononegavirales: update 2016. Arch Virol. In Press.

2. Shope RE, Murphy FA, Harrison AK, Causey OR, Kemp GE, Simpson DIH, Moore DL. Two African viruses serologically and morphologically related to rabies virus. J Virol. 1970;6:690-2.

3. Kemp GE, Causey OR, Moore DL, Odelola A, Fabiyi A. Mokola virus: Further studies on IbAn 27377, a new rabies-related etiological agent of zoonosis in Nigeria. Am J Trop Hyg. 1972;21:356-9.

4. Familusi JB, Moore DL. Isolation of a rabies-related virus from the cerebrospinal fluid of a child with aseptic meningitis. Afr J Med Sci. 1972;3:93-6. 
5. Familusi JB, Osunkoya BO, Moore DL, Kemp GE, Fabiyi A. A fatal human infection with Mokola virus. Am J Trop Med Hyg. 1972;21:959-63.

6. Jackson AC. Current and future approaches to the therapy of human rabies. Antiviral Res. 2013:99:61-7.

7. Weyer J, Msimang-Dermaux V, Paweska JT, le Roux K, Govender P, Coertse J, et al. A case of human survival of rabies, South Africa. S Afr J Infect Dis. 2016. doi:10.1080/23120053.2016.1128151.

8. Johnson N, Cunningham AF, Fooks AR. The immune response to rabies virus infection and vaccination. Vaccine. 2010;28:3896-901.

9. Kgaladi J, Wright N, Coertse J, Markotter W, Marston D, Fooks AR, et al. Diversity and epidemiology of Mokola virus. PLoS Negl Trop Dis. 2013;7:e2511.

10. Meredith CD, Nel LH, Von Teichman BF. Further isolation of Mokola virus in South Africa. Vet Record. 1996;138:119-20.

11. Foggin CM. Atypical rabies virus in cats and a dog in Zimbabwe. Vet Record. 1982;110:338.

12. Foggin CM. Rabies and rabies-related viruses in Zimbabwe: Historical, virological and ecological aspects, PhD thesis. Harare: University of Zimbabwe; 1988.

13. Dean DJ, Abelseth MK, Atansiu P. The fluorescent antibody test. In: Meslin FC, Kaplan MM, Koprowski H, editors. Laboratory techniques in rabies. 4th ed. Geneva: World Health Organization; 1996. p. 88-95.

14. Coertse J, Weyer J, Nel LH, Markotter W. Improved PCR methods for detection of African rabies and rabies-related lyssaviruses. J Clin Microbiol. 2010;48:3949-55.

15. Hall TA. BioEdit: a user-friendly biological sequence alignment editor and analysis program for Windows 95/98/NT. Nucleic Acids Sym Ser. 1999:41:95-8.

16. Darriba D, Taboada GL, Doallo R, Posada D. jModelTest2: more models, new heuristics and high-performance computing. Nat Methods. 2012;9(8):772

17. Drummond AJ, Suchard MA, Xie D, Rambaut A. Bayesian phylogenetics with BEUTi and the BEAST 1.7. Mol Biol Evol. 2012;29(8):1969-73.

18. Webster WA, Casey GA. Virus isolation in neuroblastoma cell culture. In: Meslin FC, Kaplan MM, Koprowski H, editors. Laboratory techniques in rabies. 4th ed. Geneva: World Health Organization; 1996. p. 96-103.

19. Markotter W, Kuzmin I, Rupprecht CE, Randles J, Sabeta CT, Wandeler Al, et al. Isolation of Lagos bat virus from water mongoose. Emerg Infect Dis. 2006;12:1913-8.

20. Nel LH. Factors impacting the control of rabies. Microbiol Spec. 2013. doi:10. 1128/microbiolspec.OH-0006-2012.

21. Von Teichman BF, de Koker WC, Bosch SJE, Bishop GC, Meredith CD, Bingham J. Mokola virus infection: description of recent South African cases and a review of the virus epidemiology. S Afr Vet Assoc. 1998;69:169-71.

22. Von Teichman BF, Thomson GR, Meredith CD, Nel LH. Molecular epidemiology of rabies virus in South Africa: evidence for two distinct virus groups. J Gen Virol. 1995;76:73-82.

23. Coetzee $\mathrm{P}, \mathrm{Nel} \mathrm{LH}$. Emerging epidemic dog rabies in coastal South Africa: $\mathrm{A}$ molecular epidemiological analysis. Virus Res. 2007;126:186-95.

24. Kemp GE, Moore DL, Isoun TT, Fabiyi A. Mokola virus: Experimental infection and transmission studies with the shrew, a natural host. Arch Gesamte Virusforsch. 1973;43:242-50

25. Banyard AC, Evans JS, Luo TR, Fooks AR. Lyssaviruses and bats: Emergence and zoonotic threat. Viruses. 2014;6:2974-90.

26. Rupprecht CE, Turmelle A, Kuzmin IV. A perspective on lyssavirus emergence and perpetuation. Curr Opin Virol. 2011;1:1-9.

\section{Submit your next manuscript to BioMed Central and we will help you at every step:}

- We accept pre-submission inquiries

- Our selector tool helps you to find the most relevant journal

- We provide round the clock customer support

- Convenient online submission

- Thorough peer review

- Inclusion in PubMed and all major indexing services

- Maximum visibility for your research

Submit your manuscript at www.biomedcentral.com/submit
Biomed Central 